\title{
A review of toolkits and case definitions for detecting enteric fever outbreaks in Asian and African countries from 1965-2019
}

\author{
Asif Khaliq ${ }^{1,4}$, Mohammad \\ Tahir Yousafzai ${ }^{1,2}$, Salman \\ $\mathrm{Haq}^{3}$, Rahima Yaseen ${ }^{3}$, \\ Sonia Qureshi ${ }^{1}$, Fahad \\ Rind ${ }^{1}$, Zahra A Padhani ${ }^{5}$, \\ Ayub Khan ${ }^{1}$, Abdul \\ Momin Kazi ${ }^{1}$, Farah Naz \\ Qamar $^{1}$
}

${ }^{1}$ Department of Pediatrics and Child Health, The Aga Khan University Hospital, Aga Khan University Karachi, Pakistan ${ }^{2}$ Kirby Institute, University of New South Wales, Australia 3Ziauddin Medical College, Ziauddin University Karachi, Pakistan

${ }^{4}$ School of Public Health and Social Work, Queensland University of Technology, Brisbane, Australia ${ }^{5}$ Institute of Global Health and Development, Aga Khan University Hospital, Karachi

\section{Correspondence to:}

Asif Khaliq

School of Public Health \&

Social Work,

The Queensland University of Technology,

Kelvin Grove, 4059, QLD, Australia, asifkhaliq7@gmail.com

asif.khaliq@hdr.qut.edu.au
Background This review assessed the case definitions, diagnostic criteria, antimicrobial resistance, and methods used for enteric fever outbreaks and utilization of any unified outbreak score or checklist for early identification and response in Asia and Africa from 1965-2019.

Methods We searched enteric fever outbreaks using PubMed, Google Scholar, and the Cochrane library. Studies describing a single outbreak event of enteric fever in Asia and Africa from 1965-2019 were reviewed. We excluded case reports, letter to editors, studies reporting typhoid in conjunction with other diseases, the Centers for Disease Control and Prevention (CDC) trip reports, the World Health Organization (WHO) bulletins report, data from mathematical modeling and simulation studies, reviews and ProMed alert. Also, non-typhoidal salmonella outbreaks were excluded.

Results A total of 5063 articles were identified using the key terms and 68 studies were selected for data extraction. Most $(48,71 \%)$ outbreaks were from Asian countries, 20 (29\%) were reported from Africa. Only 15 studies reported the case definition used for case identification during an outbreak and 8 of those were from Asia. A third (20,29\%) of the studies described antibiotic resistance pattern. 43 (63\%) studies contained information regarding the source of the outbreak. Outcomes (hospitalization and deaths) were reported in a quarter of studies. Only 23 (29\%) of the studies reported outbreak control strategies while none reported any unified outbreak score or a checklist to identify the outbreak.

Conclusion This review highlights the variability in detection and reporting methods for enteric fever outbreaks in Asia and Africa. No standardized case definitions or laboratory methods were reported. Only a few studies reported strategies for outbreak control. There is a need for the development of a unified outbreak score or a checklist to identify and report enteric fever outbreaks globally.

Enteric fever is a major public health concern especially in low middle-income countries (LMICs) [1]. The disease is caused by subspecies enterica serovar Typhi (S. typhi) and Paratyphi (S. paratyphi). Typhi is responsible for causing typhoid fever, while Enteric fever is a group of enteric infection caused by Salmonella enterica. The Salmonella enterica has different subspecies serovars, which are responsible to cause varying types of enteric infections, such as typhoid fever by S. typhi and paratyphoid fever by S. paratyphi A, B, and C [2,3]. The disease is characterized by high-grade fever, fatigue, malaise, headache, and certain gastrointestinal symptoms including abdominal pain, diarrhea, or constipation $[3,4]$. The disease is highly endemic in most of the LMICs. Compared with industrialized nations, 
people living in Asian and African countries are vulnerable to enteric fever. Despite having high endemicity of enteric fever, the disease cannot be diagnosed clinically from the clinical sign and symptoms [5].

The symptoms of enteric fever are non-specific and are closely relate to other febrile illnesses, such as malaria, dengue, and influenza [5]. Clinicians preferred to diagnose enteric fever with serological and other laboratory tests for diagnosing enteric fever. The Widal test, Typhi dot and Tubex-M test are the commonly prescribed serological tests for the initial diagnosis of enteric fever [6]. However, for the confirmatory diagnosis of enteric fever, blood, bone marrow or other body specimen is recommended. Among different body specimen, the bone marrow culture has the highest sensitivity of $96 \%$ for Salmonella species. Despite bone marrow culture highest sensitivity, blood culture is considered as the gold standard for the confirmatory diagnosis of enteric fever, because it is less invasive compared with bone marrow culture. The culture sensitivity of blood culture decreased to around 30\% from 60\% in patients having less than a week symptoms history and in patients with a history of antimicrobial use [7-10]. The rising antimicrobial resistance against $S$. typhi is a global threat. The antimicrobial agents, such as amoxicillin, chloramphenicol and co-trimoxazole served as the first line of choice for treating enteric fever, however, globally more than a third of the population is resistant to these agents $[1,11]$. Enteric fever patients who are resistant to amoxicillin, chloramphenicol and co-trimoxazole are found to have Multidrug Resistance (MDR) enteric fever [12]. The emergence of MDR enteric fever in the late 1980s and the early 1990s has shifted the therapeutic choice to second-generation fluoroquinolones and third-generation cephalosporins $[13,14]$. Still, the issues related to therapeutic failure reported due to the emergence of Fluoroquinolones resistance (FQR) and Extensive Drug Resistance (XDR) $[11,14,15]$. The XDR enteric fever was first observed in November 2016 from the southern parts of Pakistan. The therapeutic management of XDR enteric fever seems like a medical challenge for the health practitioners, because of the limited choice of antibiotics. In general, the macrolides (Azithromycin) and carbapenems (Meropenem or Imipenem) are recommended for treating XDR enteric fever cases [16-18].

The global burden of enteric fever is not homogenous. Most of the Asian and African countries are highly endemic to enteric fever. The incidence rate of enteric fever in most of the Asian and African countries ranged from 100 to 700 per 100000 population, while the incidence rate of enteric fever in other regions is less than 15 per 100000 [3]. Factors, such as living in urban slums, inaccessibility to safe drinking water, restaurant or cafeteria food, close contact with enteric fever patients and prior use of antibiotics significantly increased the risk of enteric fever [18,19]. People living in Asian, African, and Latin American countries are deprived of safe drinking water, adequate sanitation, and proper shelter, which in turn are responsible for many communicable and infectious diseases including enteric fever $[19,20]$. In this regard, it is essential to know about the case definitions, diagnostic criteria, antimicrobial resistance, methods used for outbreaks control and use of any unified outbreak scoring or a checklist for the identification of enteric fever outbreaks in Asia and Africa from 1965-2019.

\section{METHODS}

We searched PubMed, Google Scholar and the Cochrane library using a combination of Medical Subjects Heading (MeSH) and Keywords, i.e, "Salmonella Infections" [Mesh] OR "Typhoid Fever" [Mesh] OR "Paratyphoid fever" OR "Enteric fever" AND "Disease Outbreaks"[Mesh] OR outbreak*. In addition, filters for the publication year from 1965 to May 25, 2019, English language and human studies were used (where applicable) (Supplementary file 1). All studies indicating documentation of clinical features, based on title and/or abstract, were retrieved in the full text where available.

We conducted a parallel search to examine the included studies reference lists and pertinent systematic reviews for additional studies.

\section{Eligibility criteria}

We considered original research articles that described at least one outbreak event of enteric fever in humans from 1965 to May 2019. We included all those studies that described enteric fever (typhoid or paratyphoid) outbreak event in Asia and Africa irrespective of age, gender, institutional setting, treatment method and source of transmission. Studies with enteric fever cases identified based on clinical criteria alone or confirmed by culture (blood, bone marrow, stool, or any other sterile fluid) or serology (Widal test/Typhi Dot test), were included. We excluded case reports studies using a clinical diagnosis only, letter to editors, studies reporting typhoid in conjunction with other diseases, CDC trip reports, WHO bulletins report, data from mathematical modeling and simulation studies, reviews and ProMed alerts (Table 1). 
Table 1. List of exclusion criteria

\section{CASE-REPORTS}

Editorial and letters to the editor

Newspaper reports

Book chapters

Non-human studies

Not published in the English language

Reports or bulletin of WHO, CDC and ProMed alerts

Enteric fever outbreaks before 1965

Studies showing no evidence of enteric fever outbreak

outbreaks due to Non-typhoid Salmonella

Enteric fever outbreaks outside -Asia and Africa

other diseases discussed along with enteric fever outbreak

Mathematical Modeling and simulation studies

Outbreaks from the same hospital/region and during the same period were considered once

Same hospital/region and during the same period were considered

Narrative reviews

Systematic reviews
Studies published from the same hospital/region and during the same time were considered as duplicate/overlapping data and counted once.

\section{Screening process}

All papers searched through different databases were imported into the endnote library. Duplicate records were removed. Two co-authors (AK and FR) independently initiated the screening of the papers. In the first step, titles and abstracts were independently screened and ineligible records were excluded. At the end of the first phase of screening, both reviewers met and discussed the papers included and excluded. The third reviewer (ZF) resolved any disagreements between the two independent reviewers. The second screening was based on a full-text review of the remaining papers. Again, AK and FR reviewed the full text of all papers and any paper not fulfilling the eligibility criteria was excluded. Disagreements between the two reviewers were resolved by the third reviewer (ZF). The remaining papers after the second screening were used for data extraction. The whole screening process with the number of records is provided in the PRISMA flowchart (Figure 1).

\section{Data extraction, management, and analysis}

We created an excel sheet for data extraction. The excel sheet included variables such as first author name, year of publication, country of publication, study design, the case definition for enteric fever, number of cases based on culture confirmation, serological testing and/or clinical suspected, diagnostic methodology used for identifying the outbreak, tool or a unified score system to identify the outbreak, source of the outbreak (water or food item reported as the source for transmitting the outbreak), number of hospitalizations (number of studies reporting any hospitalization and the proportion of affected people hospitalized for typhoid during the outbreak), antimicrobial resistance or sensitivity, control measures, the effectiveness of the control measures or strategies in containing the outbreak. Data extraction was performed by the two co-authors (SH and RY) and any disagreements in data extraction were addressed by the third co-author SQ.

Extracted data were classified into studies based on reported outcomes, age distribution, and geographical regions and by the outbreak periods. Frequency tables by country and region for each outcome variable were tabulated in Microsoft Excel latest version (Microsoft Inc, Seattle, WA, USA).

\section{RESULTS}

A total of 5063 studies were extracted (2506 from PubMed, 2545 from Cochrane library and 12 studies were from Google Scholar). Additional 56 records were identified through cross-referencing, making the total records $\mathrm{N}=5119$. There were 62 duplicates, which were removed, and the remaining 5057 records were used

Figure 1. PRISMA flow diagram. 
for screening. The selection process is illustrated in the PRISMA study flow diagram (Figure 1). A total of 68 studies were included for the final review.

55 studies were selected based on more than one inclusion criteria.

\section{Geographical Distribution of Enteric Fever Outbreak in Asia and Africa}

Of the 68 selected studies, 48 were from Asia and 20 from Africa. Spatial distribution of the outbreaks is presented in the geospatial map (Figure 2).

The first outbreak of enteric fever from Asia was reported from India in 1975 while in Africa, it was reported from South Africa in 1978. From 1976 to 1986, 5 studies regarding outbreaks were identified, 3 from Asia and 2 from Africa. The number of outbreak studies retrieved increased continuously in the succeeding decades ie, 17, 19 and 26 in the periods1987-97, 1998-08, and 2009-19 respectively.

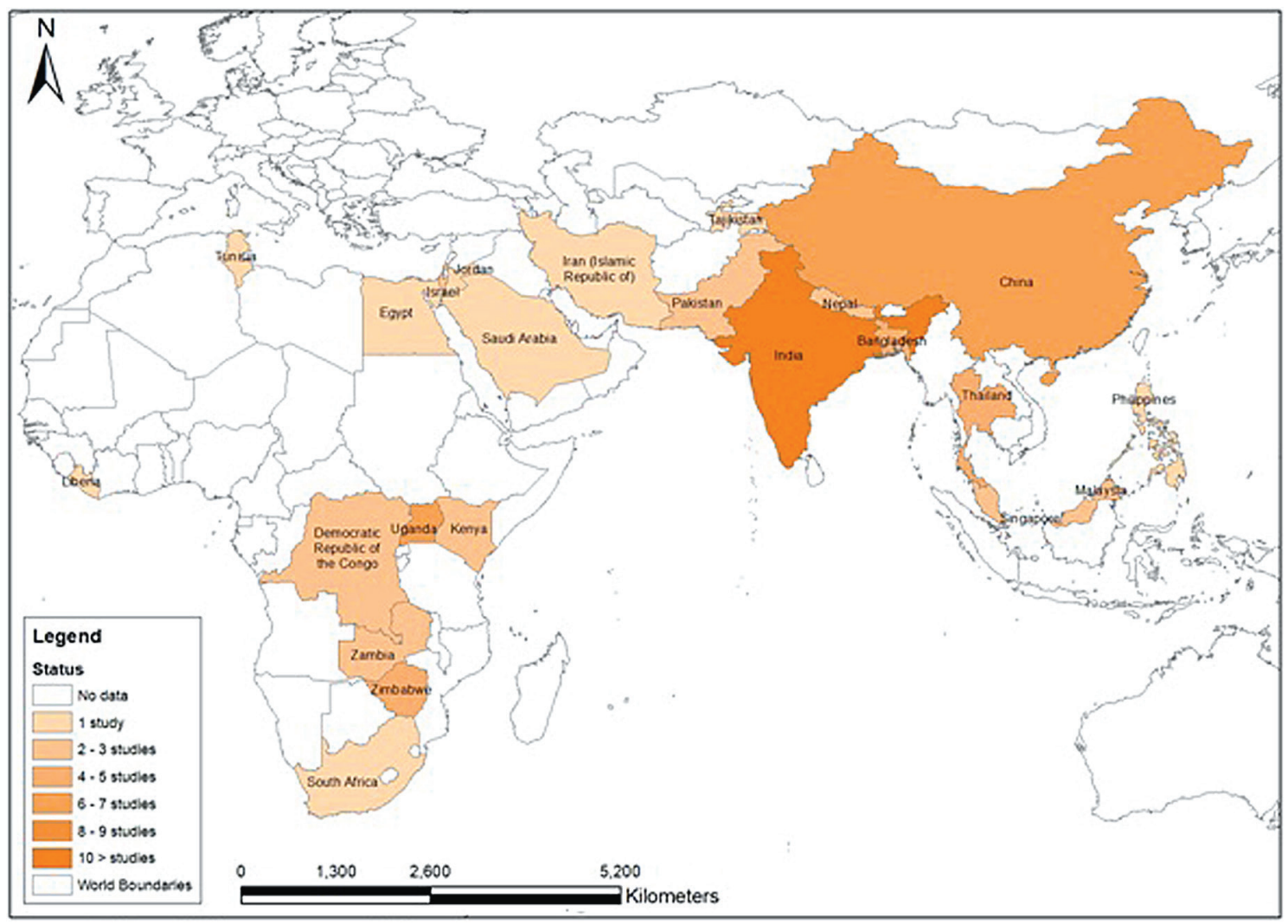

Figure 2. Geographical distribution of Enteric fever outbreaks in different countries of Asia and Africa.

\section{Enteric fever case definitions}

There were 15 studies, which reported a case definition of enteric fever for the identification of cases in the outbreak. Among these 15 studies, 8 (53\%) studies were from Asia and 7 (47\%) from Africa.

Presence of fever along gastrointestinal disorders (ie, abdominal discomfort, diarrhea, constipation, nausea, vomiting) as case definition criteria for enteric fever was used in seven papers from 6/7 (86\%) from Africa and $1 / 8(12.5 \%)$ from Asia. Fever exceeding $37.5^{\circ} \mathrm{C}$ or $38.0^{\circ} \mathrm{C}$ for more than 3 days was used as a case definition in two studies. In six studies fever greater than $38^{\circ} \mathrm{C}$ was either alone or along with headache. The various case definitions used are presented in Table 2.

2-3 African studies used the presence of intestinal perforation, negative malarial parasite test and failure to respond to anti-malarial treatment as a definition of enteric fever. Table 1 shows the details of clinical signs used for defining a case of enteric fever in an outbreak setting. None of the studies reported the use of any unified scoring or a tool for the identification of enteric fever outbreak. 
Table 2. Clinical signs used for defining a case of enteric fever in an outbreak $(n=15)$

\begin{tabular}{|c|c|c|c|c|c|c|c|c|c|c|c|c|c|c|}
\hline \multirow[b]{2}{*}{ 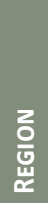 } & \multirow[b]{2}{*}{$\begin{array}{l}\text { COUNTRY } \\
\text { NAME }\end{array}$} & \multirow[b]{2}{*}{$\begin{array}{l}\text { YEAR OF } \\
\text { OUTBREAK }\end{array}$} & \multicolumn{12}{|c|}{ CLINICAL OR SUSPECTED SYMPTOMS } \\
\hline & & & $\underset{\varpi}{\stackrel{m}{*}}$ & 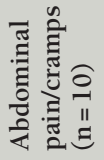 & 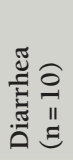 & 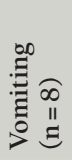 & 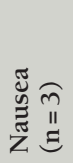 & 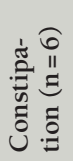 & 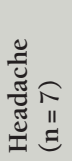 & 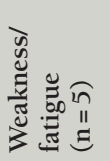 & 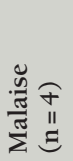 & 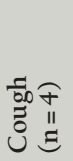 & 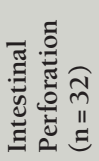 & 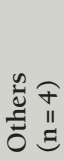 \\
\hline \multirow{7}{*}{ 曾 } & Uganda & 2009 & $*$ & * & & $\dagger$ & & & $\dagger$ & $\dagger$ & & & $\dagger$ & $\dagger$ \\
\hline & Uganda & $2009-2011$ & $*$ & * & & & & & $\dagger$ & $\dagger$ & & & $\dagger$ & $\dagger$ \\
\hline & Zimbabwe & $2011-2012$ & * & $\dagger$ & $\dagger$ & & & $\dagger$ & $*$ & & $*$ & * & & \\
\hline & Zimbabwe & 2012 & $*$ & $\dagger$ & $\dagger$ & & & $\dagger$ & $*$ & & $*$ & $*$ & & $*$ \\
\hline & Zimbabwe & 2012 & $*$ & & $\dagger$ & $\dagger$ & & $\dagger$ & $\dagger$ & & $*$ & * & & \\
\hline & Uganda & 2015 & $*$ & $\dagger$ & $\dagger$ & $\dagger$ & $\dagger$ & $\dagger$ & $\dagger$ & $\dagger$ & & & & $\dagger$ \\
\hline & Zambia & 2017 & $*$ & $*$ & $\dagger$ & $\dagger$ & & $\dagger$ & & $\dagger$ & & & & \\
\hline \multirow{8}{*}{$\frac{\sqrt[3]{3}}{4}$} & Israel & 1985 & $*$ & & & & & & & & & & & \\
\hline & Jordan & 1989 & $*$ & & $\dagger$ & $\dagger$ & & & & & & & & \\
\hline & Myanmar & 2000 & $*$ & $\dagger$ & $\dagger$ & & & $\dagger$ & & & & & & \\
\hline & Nepal & $2002-2004$ & $*$ & & & & & & & & & & & \\
\hline & Pakistan & 2004 & $*$ & $*$ & $*$ & $*$ & & & & $*$ & & & & \\
\hline & Singapore & 2007 & $\dagger$ & $\dagger$ & $*$ & $\dagger$ & $\dagger$ & & & & & & & \\
\hline & Singapore & 2007 & & $\dagger$ & $*$ & $\dagger$ & $\dagger$ & & & & & & & \\
\hline & China & 2010 & $*$ & & & & & & $*$ & & & & & \\
\hline
\end{tabular}

* Studies support that the sign must be present.

† Studies support that the sign may be present along with other symptoms.

\section{Enteric fever laboratory diagnostic methods}

Only 25 studies provided information regarding enteric fever laboratory confirmation. Out of which, 17/25 (68\%) studies were from Asia and 9/25 (36\%) were of African origin. The definition for a laboratory-confirmed case of enteric fever was presented by only $3 / 25(12 \%)$ studies, where a laboratory-confirmed case was defined as the presence of S. typhi or $S$. paratyphi in the blood $(n=3)$, stool $(n=3)$ or any other body fluids cultures urine $(n=2)$ and bone-marrow $(n=1)$. However, there were 4/25 (16\%) studies in which screening test, such as, Widal test and Tubex TF were performed. The screening test performed in Asian countries was the Widal test, whereas in African studies Tubex TF was commonly advised. Out of these four studies, only one presented probable case definition of enteric fever based on a positive serological test (Widal's test, typhidot, tubex). There were 20/25 (80\%) studies in which blood culture ordered for the confirmation of enteric fever (Table 3).

\section{Antimicrobial resistance of enteric fever}

20 studies, 15(75\%) from Asia and 5 (25\%) from Africa reported the antimicrobial sensitivity pattern of the isolates identified in the outbreak. 15 (75\%) studies reported MDR isolates, 4 (20\%) reported FQR, and one (5\%) study reported XDR S. typhi isolate during the outbreak.

In the Asian region, the first reported case of MDR was observed in Pakistan in 1988. Later, a series of MDR isolates were reported from other Asian countries: Bangladesh in 1989, India in 1990, Iran in 1992, Tajikistan in 1997, Thailand in 1999, Nepal in 2002 and China in 2006. In African countries, MDR was first observed in 2004 in Kenya and later in Uganda in 2011. The cases of FQR were first reported from Tajikistan in 1997, followed reports from Kenya and Nepal also. (Table 4).

\section{Enteric fever outbreak source investigation}

Out of 68 selected studies, a total of $41(60 \%)$ studies contained information regarding the source of enteric fever outbreak. Among these 41 studies, 33 (80\%) were of Asian origin while 8 (20\%) were from Africa. In addition, there were 11 (25\%) studies, in which more than one source of the outbreak was reported. The sources of outbreaks were broadly categorized into 4 categories: water contamination, food contamination, carrier transmission and inappropriate sanitation $\&$ hygiene. Table 4 shows the sources of the outbreaks by country and regions.

Inappropriate sanitation and water contamination were identified as the major cause of enteric fever outbreaks in both Asian and African countries. There were 20 (50\%) and 17 (41\%) studies in which inappropri- 
Table 3. Screening and diagnostic test for enteric fever investigation $(n=25)$

\begin{tabular}{|c|c|c|c|c|c|c|c|c|}
\hline \multirow[b]{2}{*}{ REGION } & \multirow[b]{2}{*}{$\begin{array}{l}\text { COUNTRY } \\
\text { NAME }\end{array}$} & \multirow{2}{*}{$\begin{array}{l}\text { YEAR OF } \\
\text { OUTBREAK }\end{array}$} & \multicolumn{2}{|c|}{ SCREENING TEST } & \multicolumn{4}{|c|}{ LABORATORY CONFIRMED TEST } \\
\hline & & & $\begin{array}{l}\text { Widal test } \\
\quad(n=3)\end{array}$ & $\begin{array}{l}\text { Tubex TF test } \\
\qquad(\mathrm{n}=1)\end{array}$ & $\begin{array}{l}\text { Blood culture } \\
\qquad(\mathrm{n}=20)\end{array}$ & $\begin{array}{l}\text { Stool culture } \\
\qquad(\mathrm{n}=12)\end{array}$ & $\begin{array}{l}\text { Urine culture } \\
\qquad(\mathrm{n}=5)\end{array}$ & $\begin{array}{l}\text { Others } \\
(n=3)\end{array}$ \\
\hline \multirow{8}{*}{$\begin{array}{l}\text { Africa } \\
(\mathrm{n}=8)\end{array}$} & Tunisia & 2004-05 & & & $*$ & $*$ & & \\
\hline & Zimbabwe & 2007 & & & $*$ & * & * & \\
\hline & Uganda & 2009 & & $*$ & $*$ & & & \\
\hline & Uganda & 2009 & & & $*$ & $*$ & & \\
\hline & Zambia & $2010-12$ & & & $*$ & $*$ & & \\
\hline & Zimbabwe & 2011 & & & $*$ & * & $*$ & \\
\hline & Zimbabwe & 2012 & & & $*$ & & & \\
\hline & Zambia & 2017 & & & & * & & \\
\hline \multirow{17}{*}{$\begin{array}{l}\text { Asia } \\
(n=17)\end{array}$} & Singapore & 1979 & & & $*$ & $*$ & $*$ & \\
\hline & Israel & 1985 & & & $*$ & & & \\
\hline & Pakistan & 1988 & & & $*$ & & & \\
\hline & Bangladesh & $1989-90$ & $*$ & & $*$ & & & $\dagger$ \\
\hline & India & 1990 & & & $*$ & & & \\
\hline & India & 1997 & & & $*$ & & & \\
\hline & India & 2000 & $*$ & & $*$ & & & \\
\hline & Nepal & 2002 & & & $*$ & & & \\
\hline & China & 2004 & & & & & & 韦 \\
\hline & Singapore & 2007 & & & & * & & \\
\hline & Singapore & 2007 & & & & $*$ & & \\
\hline & China & 2010 & & & $*$ & $*$ & & \\
\hline & India & 2010 & & & $*$ & $*$ & $*$ & $\S$ \\
\hline & Myanmar & 2010 & & & $*$ & & & \\
\hline & Malaysia & 2012 & & & & $*$ & & \\
\hline & India & 2013 & & & $*$ & & & \\
\hline & India & 2014 & $*$ & & $*$ & & & \\
\hline
\end{tabular}

†Bone marrow.

†Gall bladder fluid.

§Rectal swab.

Table 4. Enteric fever drug resistance $(\mathrm{N}=20)$

\begin{tabular}{|c|c|c|c|c|c|c|}
\hline $\begin{array}{l}\text { REGIONAL } \\
\text { DIVISION }\end{array}$ & COUNTRY & $\begin{array}{l}\text { YEAR OF } \\
\text { OUTBREAK }\end{array}$ & $\begin{array}{c}\text { MDR } \\
(\mathrm{N}=15)\end{array}$ & $\begin{array}{c}\text { FQR } \\
(N=4)\end{array}$ & $\begin{array}{c}\text { XDR } \\
(\mathrm{N}=0)\end{array}$ & $\begin{array}{l}\text { OTHER } \\
(\mathrm{N}=4)\end{array}$ \\
\hline \multirow{5}{*}{ Africa $(n=5)$} & Kenya & 2004 & * & & & $\dagger \dagger$ \\
\hline & Tunisia & 2004 & - & - & - & - \\
\hline & Uganda & 2009 & - & - & - & - \\
\hline & Uganda & 2011 & $*$ & & & \\
\hline & Kenya & 2014 & & 丰 & & \\
\hline \multirow{15}{*}{ Asia $(n=15)$} & Pakistan & 1988 & $*$ & & & \\
\hline & Bangladesh & 1989 & $*$ & & & \\
\hline & Bangladesh & 1990 & $\dagger$ & & & \\
\hline & Bangladesh & 1990 & $*$ & & & \\
\hline & India & 1990 & $*$ & & & \\
\hline & Bangladesh & 1992 & $*$ & & & \\
\hline & Iran & 1992 & $*$ & & & \\
\hline & Tajikistan & 1997 & * & $\S$ & & $\|$ \\
\hline & Thailand & 1999 & $*$ & & & $\|$ \\
\hline & India & 2000 & $*$ & & & II \\
\hline & Nepal & 2002 & $*$ & $*$ & & \\
\hline & China & 2006 & $*$ & & & \\
\hline & Nepal & 2009 & & $\S$ & & \\
\hline & Thailand & 2009 & - & - & - & - \\
\hline & India & 2010 & $*$ & & & \\
\hline
\end{tabular}

MDR - multidrug resistance, FDR - fluoroquinolone drug resistance, XDR - extensive drug resistance

†Strains were resistant to chloramphenicol.

¥Resistance to ciprofloxacin $54 \%$ in tested strains.

$\S$ Strains were resistant to nalidisic acid but sensitive to floroquinolones.

IIStrains were resistant to streptomycin and tetracycline.

IStrains were resistant to tetracycline. ate sanitation and fecal contamination of drinking water were identified as the leading cause for the spread of the enteric fever. Similarly, there were 12 (29\%) studies in which food contamination was identified as other associated cause for enteric fever outbreak transmission. Different food items responsible for the spread of enteric fever outbreak were cowpea salad, coconut milk, cream cake, dessert buns, fish, mashed potatoes, meat, mousse cake, noodles, oysters, raw chicken, raw pork, raw vegetables, rice, and sweets. The food-borne enteric fever outbreaks were only reported from Asian countries and were observed in China, India, Jordan, Singapore, Saudi Arabia, and India. There were 6 (15\%) studies that testified transmission of enteric fever from person to person, ie, close contact with Typhi positive cases, food caterer or cook (Table 5).

\section{Preventive measures for the control of enteric fever}

The information regarding different preventive strategies for controlling enteric fever outbreak was presented by 15 (36\%) studies. The different preventive strategies used as a response to 
Table 5. Reporting source of enteric fever outbreak by country and region $(n=41)$

\begin{tabular}{|c|c|c|c|c|c|c|}
\hline \multirow[b]{2}{*}{$\begin{array}{l}\text { REGIONAL } \\
\text { DIVISION }\end{array}$} & \multirow[b]{2}{*}{$\begin{array}{l}\text { COUNTRY } \\
\text { NAME }\end{array}$} & \multirow[b]{2}{*}{$\begin{array}{l}\text { YEAR OF } \\
\text { OUTBREAK }\end{array}$} & \multicolumn{4}{|c|}{ SOURCE OF OUTBREAK } \\
\hline & & & $\begin{array}{l}\text { Drinking } \\
\text { water } \\
\text { contam- } \\
\text { ination } \\
(\mathrm{n}=17)\end{array}$ & $\begin{array}{l}\text { Food } \\
\text { contam- } \\
\text { ination } \\
(\mathrm{n}=12)\end{array}$ & $\begin{array}{l}\text { Trans- } \\
\text { mission } \\
\text { through } \\
\text { carriers } \\
(n=6)\end{array}$ & $\begin{array}{l}\text { Inappro- } \\
\text { priate } \\
\text { sanita- } \\
\text { tion and } \\
\text { hygiene } \\
(\mathrm{n}=20)\end{array}$ \\
\hline \multirow{8}{*}{$\begin{array}{l}\text { Africa } \\
(n=8)\end{array}$} & South Africa & 1978 & & & $*$ & \\
\hline & Uganda & 2009 & $*$ & & & \\
\hline & $\begin{array}{l}\text { Democratic } \\
\text { Republic of } \\
\text { Congo (DRC) }\end{array}$ & 2011 & $*$ & & & $*$ \\
\hline & Zimbabwe & 2011 & $*$ & & & $*$ \\
\hline & Zimbabwe & 2012 & & & & $*$ \\
\hline & Kenya & 2014 & & & & $*$ \\
\hline & Uganda & 2015 & * & & & \\
\hline & Zambia & 2017 & $*$ & & & $*$ \\
\hline \multirow{33}{*}{$\begin{array}{l}\text { Asia } \\
(n=33)\end{array}$} & India & 1975 & & & & $*$ \\
\hline & Singapore & 1979 & & $*$ & & \\
\hline & Israel & 1986 & & & & $*$ \\
\hline & Pakistan & 1988 & $*$ & & & \\
\hline & Saudi Arabia & 1988 & & $*$ & & \\
\hline & Jordan & 1989 & & $*$ & & \\
\hline & India & 1991 & & & & $*$ \\
\hline & Thailand & 1991 & & & & $*$ \\
\hline & Pakistan & 1992 & & & $*$ & $*$ \\
\hline & India & 1995 & & & & $*$ \\
\hline & Singapore & 1996 & & $*$ & & \\
\hline & India & 1997 & $*$ & & & \\
\hline & Tajikistan & 1997 & $*$ & $*$ & & $*$ \\
\hline & Thailand & 1999 & & & & $*$ \\
\hline & Myanmar & 2000 & * & & * & $*$ \\
\hline & China & 2004 & * & & * & $*$ \\
\hline & China & 2004 & * & & & \\
\hline & Pakistan & 2004 & $*$ & & & \\
\hline & India & 2005 & & & & $*$ \\
\hline & China & 2006 & $*$ & & & \\
\hline & India & 2007 & & & & $*$ \\
\hline & Singapore & 2007 & & $*$ & & \\
\hline & Singapore & 2007 & & $*$ & & \\
\hline & Philippines & 2008 & $*$ & & & \\
\hline & Malaysia & 2009 & & & & $*$ \\
\hline & Nepal & 2009 & & & $*$ & \\
\hline & China & 2010 & $*$ & $*$ & & \\
\hline & China & 2010 & & $*$ & & \\
\hline & Malaysia & 2012 & & & & $*$ \\
\hline & China & 2013 & & $*$ & & \\
\hline & India & 2013 & $*$ & $*$ & $*$ & \\
\hline & India & 2014 & $*$ & & & $*$ \\
\hline & China & 2015 & & $*$ & & \\
\hline
\end{tabular}

the outbreak were health education, mass immunization, building and construction of sewerage plant and pipelines, water disinfection and legislations to control the progression of the outbreak (Table 6).

\section{DISCUSSION}

In this systematic review, we observed only 68 studies published from 1965 to 2019 were eligible for data extraction. Likewise, outbreaks of enteric fever occurred in geographical clusters, resulting in the majority of the reports from only a few large countries such as India and China. While there were no reports of enteric fever outbreaks available until 1975, in the succeeding decades a continuous increment in the number of reported outbreaks of enteric fever was observed. No standard case definitions for a line listing of suspected or confirmed cases of enteric fever, laboratory testing, unified outbreak scoring system, or a checklist was used for the identification of enteric fever outbreak. The finding of this systematic review including published literature from the last 50 years has important public health and clinical implications, calling for an urgent need for the development of a unified scoring system or checklist for the identification of enteric fever outbreaks globally. The development of such a unified outbreak scoring system or checklist will not only facilitate the early and timely identification of the outbreaks possible, but it will also make the reporting and comparison of data across different countries a reality.

In Asian countries, the outbreaks of enteric fever occurred in geographical clusters. This spatial clustering was observed during the outbreak from 1987 to 1991 in China, Pakistan, India, and Bangladesh. This depicts the risk that an outbreak reported in one geographical boundary may penetrate to a neighboring geographical area as well. Around $70 \%$ of studies demonstrated that water contamination and inappropriate sanitary measures were the identified source of transmission. This was also supported by other studies where the disease is highly endemic because of lack of sanitary measures and access to clean water $[35,36]$. The risk factors of enteric fever vary within the geographical boundary [35] and no TRFs (Typhoid Risk Factor stratification) has been used or developed to identify inter-countries risk factor or source of transmission.

The increase in the number of enteric fever outbreaks in each succeeding decade could be because of the increase in publication trend, reporting, and availability of online supplements. While no reports eligible for inclusion in this study were found during the first decade (1965-75), a gradually increasing number of papers published on enteric fever outbreak was found from 1976 and onwards. The changing landscape of publication tendency over time might also have resulted in the publication of only severe form of outbreaks to be reported in the past while minor or small outbreaks to be reported recently, causing some form of bias in our 
Table 6. Enteric fever outbreak preventive measures $(\mathrm{N}=15)$

\begin{tabular}{|c|c|c|}
\hline SOURCE OF OUTBREAK & STUDIES SUPPORTING & PLACE OF OUTBREAK \\
\hline \multirow{6}{*}{ Health education $(n=7)$} & Yan et al (2015) [21], Yan et al (2016) [22] & China $(\mathrm{n}=2)$ \\
\hline & Cherian et al (2014) [23] & India $(\mathrm{n}=1)$ \\
\hline & al-Zubaidy et al (1995) [24] & Saudi Arabia $(n=1)$ \\
\hline & Jonathan et al (1999) [25] & Tajikistan $(\mathrm{n}=1)$ \\
\hline & Mwansa et al (2017) [26] & Zambia $(\mathrm{n}=1)$ \\
\hline & Imanishi M et al (2014) [27] & Zimbabwe $(\mathrm{n}=1)$ \\
\hline \multirow{4}{*}{ Mass immunization $(n=4)$} & Yan et al (2016) [22] & China $(\mathrm{n}=1)$ \\
\hline & Meltzer et al (2013) [28] & Nepal $(n=1)$ \\
\hline & Goh et al (1992) [29] & Singapore $(n=1)$ \\
\hline & Bodhidatta et al (1987) [30] & Thailand $(\mathrm{n}=1)$ \\
\hline \multirow{5}{*}{$\begin{array}{l}\text { Water disinfection and sanitary measures } \\
(\mathrm{n}=7)\end{array}$} & Yan et al (2015) [21], Yan et al (2016) [22], Wang et al (2017) & China $(\mathrm{n}=3)$ \\
\hline & Cherian et al (2014) [23] & India $(\mathrm{n}=1)$ \\
\hline & Jonathan et al (1999) [25] & Tajikistan $(\mathrm{n}=1)$ \\
\hline & Mwansa et al (2017) [26] & Zambia $(\mathrm{n}=1)$ \\
\hline & Imanishi M et al (2014) [27] & Zimbabwe $(\mathrm{n}=1)$ \\
\hline \multirow{4}{*}{$\begin{array}{l}\text { Building } \& \text { construction of treatment } \\
\text { plants and pipelines }(n=4)\end{array}$} & Yan et. al, (2015) [21] & China $(\mathrm{n}=1)$ \\
\hline & Banerjee et al (2007) [31], Cherian et al (2014) [23]. & India $(\mathrm{n}=2)$ \\
\hline & Aye et al (2004) [32] & Myanmar $(n=1)$ \\
\hline & Jonathan et al (1999) [25] & Tajikistan(n=1) \\
\hline \multirow{2}{*}{ Legislation $(\mathrm{n}=3)$} & Yan et al (2016) [22], Wang et al (2017) & China $(\mathrm{n}=2)$ \\
\hline & Teoh et al (1997) [33] & Singapore $(n=1)$ \\
\hline $\begin{array}{l}\text { Others }(\mathrm{n}=1) \text { (Cholecystectomy of } \\
\text { convalescent carriers) }\end{array}$ & Goh (1981) [34] & Singapore $(n=1)$ \\
\hline
\end{tabular}

results. While this is possible, we did not find any difference in the level (geographic distribution) or severity of the outbreaks over the period.

The definition of a suspected or a clinical case of enteric fever was very heterogeneous among studies in different regions. In addition, enteric fever case definition varied within the same geographical region, highlighting the lack of a standardized case definition for use in outbreak settings. The non-specificity of the clinical definition of enteric fever was also highlighted in a recent WHO report [1]. Symptoms such as fever, abdominal discomfort, diarrhea, and nausea and vomiting were considered by more than $50 \%$ of studies as clinical criteria for diagnosis of enteric fever, however, the reporting was insufficient and inconsistent in various studies. Most outbreaks were due to an MDR isolate. An unexpectedly high number of MDR and FQR outbreaks were observed among the studies published after the 2000s., this might represent a publication bias because the number of studies published before the 2000s are very few and that cannot explain the high virulence or greater tendency of the spread of MDR isolates. Because of the limitation of reporting of outcomes and hospitalization in most outbreaks, disease severity and case-fatality rates in the outbreaks cannot be assessed [36,37].

\section{Applicability and implications for research}

Enteric fever is one of the highly endemic diseases among the Asian and African countries [38,39], but unfortunately, the regional surveillance system for the reporting of enteric fever is almost non-existent among the Asian and African countries [36,37], therefore there is a dire need to establish an association that reports incidence, prevalence, hospitalization, complications, treatment outcome and mortality of enteric fever both at the community as well as at institutional level. The clinical signs and symptoms for enteric fever case diagnosis are not specific and they are often indistinguishable from other febrile illness[40]. Therefore, a thorough review of hospital records and clinical data of all suspected, probable, and confirmed cases of enteric fever can help in standardizing the case definition of enteric fever. The syndromic definition of enteric fever would result in series of positive outcomes. Like, it would aid in reducing the false positive cases of enteric fever and would also control the irrational empirical antibiotic use. Since the emergence of MDR, FQR and XDR cases are the results of irrational use of antibiotics therefore, the controlled practice of empirical antibiotic use would be a step for prevention and control of MDR, FQR and XDR cases [41].

In this systematic review we observed substantial variation in the diagnostic testing, and lack of any unified outbreak scoring or a standardized global checklist for the early identification and impact assessment of enteric fever outbreaks. An experience from the recent Ebola outbreak in West Africa provided an important 
lesson regarding the importance of initiating public health response early at the initial stages of an outbreak. Any delay in the early stages of an outbreak can result in an exponential increase in the scale of an outbreak, causing substantial follow-on effects $[42,43]$. A validated outbreak scale with the potential to predict the risk of an outbreak of a particular disease in an early stage can be beneficial in identifying outbreaks of catastrophic potential [44]. Several studies have reported the utility of outbreak scales containing various pathogen and country-specific parameters for example the novelty of the causative agent, its virulence (resistance to available antibiotics), incidence rate, fatality rate, source of transmission, availability of treatment/vaccine, population density especially susceptible population, political stability, preparedness of local health care system to deal with the outbreak, and availability of local financial, technical and trained human resources, for the timely identification of outbreaks of other infectious diseases eg, Middle East Respiratory Syndrome coronavirus (MERS-CoV), severe acute respiratory syndrome (SARS), and Ebola [44,45]. Likewise, global risk assessment tools are available for the early detection of polio, measles and dengue outbreaks which are globally used in several endemic countries as a decision support tool for the characterization of an outbreak and prioritization of response [46-48]. We recommend the development of a unified enteric fever outbreak scoring framework for early identification and prioritization of the public health response.

The spread of disease can be prevented by identifying the population at risk. Every person is at equal risk of getting the disease, but travellers are more likely to transmit the infection to others [49,50]. International travellers from Pakistan, India, Bangladesh, Mexico, Haiti, and the Philippines largely contribute to the international transmission of typhoid fever [49]. Therefore, introducing an active immunization strategy against Typhoid can aid in controlling the spread [44] of typhoid fever from the carriers to the healthy population. The typhoid carriers living in typhoid endemic countries can transmit typhoid infection in typhoid-free communities and nations very easily [51]. Different advisory bodies of the developed nations, ie, CDC of United States of America, CATMAT (Committee to Advise Tropical Medicine and Travel) of Canada and NaTHANaC (National Travel Health Network and Center) of the United Kingdom all have recommended typhoid vaccination for travellers and high-risk group people travelling to high-risk typhoid region [52-54]. Hence, immunizing the people of developing nations against typhoid vaccine could aid in preventing the geographical penetration of the disease.

An epidemiological transition has been observed among the cases of enteric fever. Children under 15 years of age are more vulnerable to enteric fever compared to adults. Vaccination against Typhoid is the sustainable solution stated by Coalition Against Typhoid (CAT) [55]. Many studies also supported typhoid vaccination for the prevention of typhoid fever [56-58]. Thus, the typhoid vaccine will provide multiple benefits not limited to outbreak prevention, but it will also reduce antimicrobial resistance and irrational empirical treatment via broad-spectrum antibiotics [59].

In future, the researchers must focus on assessing the knowledge gap and on implementing the effectiveness of different prevention strategy for reducing the disease episodes and burden. Moreover, countries must focus on water chlorination, water plant and sewerage plant infrastructure development and legislation for proper sanitation, hygiene and vaccinations among the food handlers, health care workers, international travellers and other high-risk groups of individuals and communities. Also, there is a global need of developing a unified enteric fever outbreak scores or checklist to detect outbreak at an early stage and prioritize timely response.

\section{Strengths and limitations}

This review has certain strengths, such as the use of the breadth of databases, inclusion of original research articles reporting a single outbreak, and inclusion of last 50 years data of all typhoid, and paratyphoid outbreaks that occurred in Asia and Africa. However, the exclusion of the studies which were published in languages other than English weaken the internal validity of this review, and there are many Asian and African countries where the native language is used for scientific publication and reporting. Because of this exclusion, the literature retrieved for this study does not represent the actual outbreak events among Asian and African countries. Further, there is also a potential issue of cohort effect due to the inclusion of 50-year retrospective records eg, further back in the past you go, the less likely it is for an epidemic to be published. The cohort effect might have resulted in the bias of unknown effect and even direction, it might easily be the case that only the severe one's outbreaks were published in the past, while even smaller get published today. The problem is a constant change in the landscape including hygiene and sanitation, making the longer-term comparison less likely to be directly comparable. Moreover, due to the heterogenicity of reporting mechanism and outcomes, quality assessment and meta-analysis of was not done. 


\section{CONCLUSION}

Our review highlights the variability in detection and reporting methods for enteric fever. Case definitions and laboratory methods for the diagnosis of enteric fever cases were not standardized. There is lack of a standardized "tool kit" for containing the outbreak if an event happens. This review highlights the necessity of the development of a unified enteric fever outbreak scale or a standardized global scoring system for the early identification of an outbreak and prioritization of public health response.

Acknowledgements: We would like to acknowledge Dr Jai Das for providing technical and administrative support for our authors for this scoping review.

Funding: Not applicable.

Authorship contributions: FNQ conceived the idea, interpreted the results, and reviewed all the drafts of the manuscript. SQ, ZF and AYK wrote the protocol and assisted in cross-referencing and analysis of data. AK, FR, RY, and SH performed the literature search, screening, and data extraction. AMK guided the analysis and geospatial maps. MTY guided the methodology and discussion section. All authors read and reviewed the final version of the manuscript.

Competing interests: The authors completed the ICMJE Unified Competing Interest form (available upon request from the corresponding author), and declare no conflicts of interest.

1 Kariuki S, Gordon MA, Feasey N, Parry CM. Antimicrobial resistance and management of invasive Salmonella disease. Vaccine. 2015;33:C21-9. Medline:25912288 doi:10.1016/j.vaccine.2015.03.102

2 Klemm EJ, Shakoor S, Page AJ, Qamar FN, Judge K, Saeed DK, et al. Emergence of an extensively drug-resistant Salmonella enterica serovar Typhi clone harboring a promiscuous plasmid encoding resistance to fluoroquinolones and third-generation cephalosporins. MBio. 2018;9:e00105-18. Medline:29463654 doi:10.1128/mBio.00105-18

3 GBD 2017 Typhoid and Paratyphoid Collaborators. The global burden of typhoid and paratyphoid fevers: a systematic analysis for the Global Burden of Disease Study 2017. Lancet Infect Dis. 2019;19:369-81. Medline:30792131 doi:10.1016/S14733099(18)30685-6

4 World Health Organization. Typhoid | Key Facts 2018. Available: https://www.who.int/news-room/fact-sheets/detail/typhoid. Accessed: 1 December 2020.

5 Azmatullah A, Qamar FN, Thaver D, Zaidi AK, Bhutta ZA. Systematic review of the global epidemiology, clinical and laboratory profile of enteric fever. J Glob Health. 2015;5:020407. Medline:26649174 doi:10.7189/jogh.05.020407

6 Divyashree S, Nabarro L, Veeraraghavan B, Rupali P. Enteric fever in India: current scenario and future directions. Trop Med Int Health. 2016;21:1255-62. Medline:27495900 doi:10.1111/tmi.12762

7 Crump JA, Luby SP, Mintz ED. The global burden of typhoid fever. Bull World Health Organ. 2004;82:346-53. Medline: 15298225

8 Antillon M, Saad NJ, Baker S, Pollard AJ, Pitzer VE. The relationship between blood sample volume and diagnostic sensitivity of blood culture for typhoid and paratyphoid fever: a systematic review and meta-analysis. J Infect Dis. 2018;218:S255-S267. Medline:30307563 doi:10.1093/infdis/jiy471

9 Mogasale V, Ramani E, Mogasale VV, Park J. What proportion of Salmonella Typhi cases are detected by blood culture? A systematic literature review. Ann Clin Microbiol Antimicrob. 2016;15:32. Medline:27188991 doi:10.1186/s12941-016-0147-z

10 House D, Wain J, Ho VA, Diep TS, Chinh NT, Bay PV, et al. Serology of typhoid fever in an area of endemicity and its relevance to diagnosis. J Clin Microbiol. 2001;39:1002-7. Medline:11230418 doi:10.1128/JCM.39.3.1002-1007.2001

11 Crump JA, Sjölund-Karlsson M, Gordon MA, Parry CM. Epidemiology, clinical presentation, laboratory diagnosis, antimicrobial resistance, and antimicrobial management of invasive Salmonella infections. Clin Microbiol Rev. 2015;28:901-37. Medline:26180063 doi:10.1128/CMR.00002-15

12 Zaki SA, Sunil K. Multidrug-resistant typhoid fever: a review. J Infect Dev Ctries. 2011;5:324. Medline:21628808 doi:10.3855/ jidc. 1405

13 World Health Organization. Background document: The Diagnosis, Treatment and Prevention of Typhoid fever. Geneva: WHO; 2003.

14 Parry CM, Ribeiro I, Walia K, Rupali P, Baker S, Basnyat B. Multidrug resistant enteric fever in South Asia: unmet medical needs and opportunities. BMJ. 2019;364:k5322. Medline:30670452 doi:10.1136/bmj.k5322

15 Karkey A, Thwaites GE, Baker S. The evolution of antimicrobial resistance in Salmonella Typhi. Curr Opin Gastroenterol. 2018;34:25-30. Medline:29059070 doi:10.1097/MOG.0000000000000406

16 Chatham-Stephens K, Medalla F, Hughes M, Appiah GD, Aubert RD, Caidi H, et al. Emergence of extensively drug-resistant Salmonella Typhi infections among travelers to or from Pakistan-United States, 2016-2018. MMWR Morb Mortal Wkly Rep. 2019;68:11. Medline:30629573 doi:10.15585/mmwr.mm6801a3

17 World Health Organization. Typhoid fever - Islamic Republic of Pakistan 2018. Available: https://www.who.int/csr/don/27-december-2018-typhoid-pakistan/en/\#: :text=Pakistan\%20Health\%20Authorities\%20have\%20reported,enterica\%20serovar\%20 Typhi\%20(or\%20S. Accessed: 1 July 2020. 
18 Qamar FN, Yousafzai MT, Khalid M, Kazi AM, Lohana H, Karim S, et al. Outbreak investigation of ceftriaxone-resistant Salmonella enterica serotype Typhi and its risk factors among the general population in Hyderabad, Pakistan: a matched case-control study. Lancet Infect Dis. 2018;18:1368-76. Medline:30507460 doi:10.1016/S1473-3099(18)30483-3

19 Mogasale V, Maskery B, Ochiai RL, Lee JS, Mogasale V, Ramani E, et al. Burden of typhoid fever in low-income and middle-income countries: a systematic, literature-based update with risk-factor adjustment. Lancet Glob Health. 2014;2:e570-80. Medline:25304633 doi:10.1016/S2214-109X(14)70301-8

20 World Health Organization. Sanitation | Key Facts 2019. Available: https://www.who.int/news-room/fact-sheets/detail/sanitation. Accessed: 1 December 2020.

21 Coalition against Typhoid. About the Coalition against Typhoid 2018. Available: https://www.coalitionagainsttyphoid.org/ about-us/about-the-coalition-against-typhoid/. Accessed: 6 June 2020.

22 Lipsitch M, Siber GR. How can vaccines contribute to solving the antimicrobial resistance problem? MBio. 2016;7:e00428-16. Medline:27273824 doi:10.1128/mBio.00428-16

23 Cherian J, Sampath S, Sunderamurthy B, Chavada V, Vasudevan K, Govindasamy A. An outbreak investigation of typhoid fever in Pondicherry, South India, 2013. Int J Med Sci Public Health. 2015;4:256-61. doi:10.5455/ijmsph.2015.0000201448

24 al-Zubaidy AA, el Bushra HE, Mawlawi MY. An outbreak of typhoid fever among children who attended a potluck dinner at Al-Mudhnab, Saudi Arabia. East Afr Med J. 1995;72:373-5. Medline:7498007

25 Mermin JH, Villar R, Carpenter J, Roberts L, Samaridden A, Gasanova L, et al. A Massive Epidemic of Multidrug-Resistant Typhoid Fever in Tajikistan Associated with Consumption of Municipal Water. J Infect Dis. 1999;179:1416-22. Medline:10228063 doi:10.1086/314766

26 Mwansa F, Gama A, Kapaya F, Yard E, Kumar R, Chongwe G, et al. Typhoid fever outbreak investigation in a malaria endemic community, Solwezi, North-Western province, Zambia, 2017. Heal Press Zambia Bull. 2017;2:20-8.

27 Imanishi M, Kweza PF, Slayton RB, Urayai T, Ziro O, Mushayi W, et al. Household Water Treatment Uptake during a Public Health Response to a Large Typhoid Fever Outbreak in Harare, Zimbabwe. ASTMH. 2014;90:945-54. Medline:24664784 doi:10.4269/ajtmh.13-0497

28 Meltzer E, Stienlauf S, Leshem E, Sidi Y, Schwartz E. A Large Outbreak of Salmonella Paratyphi A Infection Among Israeli Travelers To Nepal. Clin Infect Dis. 2013;58:359-64. Medline:24198224 doi:10.1093/cid/cit723

29 Goh KT, Teo S, Tay L, Monteiro E. Epidemiology and control of an outbreak of typhoid in a psychiatric institution. Epidemiol Infect. 1992;108:2291-30. Medline:1582465 doi:10.1017/S0950268800049700

30 Bodhidatta L, Taylor DN, Thisyakom U, Echeverria P. Control of typhoid fever in Bangkok, Thailand, by annual immunization of schoolchildren with parenteral typhoid vaccine. Rev Infect Dis. 1987;9:841-5. Medline:3438648 doi:10.1093/clinids/9.4.841

31 Banerjee A, Kalghatgi AT, Singh P, Nagendra A, Singh Z, Handa SK. Epidemiological Investigation of an Outbreak of Enteric Fever. Med J Armed Forces India. 2007;63:322-4. Medline:27408039 doi:10.1016/S0377-1237(07)80005-0

32 Aye NN, Sun B, Zhu X. Study on the water quality of Kye-In Lake near the Chatthin Wildlife Sanctuary (Sagaing Division), Myanmar. NY Sci J. 2010;3:76-80.

33 Teoh YL, Goh KT, Neo KS, Yeo M. A nationwide outbreak of coconut-associated paratyphoid A fever in Singapore. Ann Acad Med Singap. 1997;26:544-8. Medline:9494656

34 Goh KT. An outbreak of paratyphoid A in Singapore: clinical and epidemiological studies. Southeast Asian J Trop Med Public Health. 1981;12:55-62. Medline:6789457

35 Corner RJ, Dewan AM, Hashizume M. Modelling typhoid risk in Dhaka Metropolitan Area of Bangladesh: the role of socio-economic and environmental factors. Int J Health Geogr. 2013;12:13. Medline:23497202 doi:10.1186/1476-072X-12-13

36 Radhakrishnan A, Als D, Mintz ED, Crump JA, Stanaway J, Breiman RF, et al. Introductory article on global burden and epidemiology of typhoid fever. Am J Trop Med Hyg. 2018;99:4-9. Medline:30047370 doi:10.4269/ajtmh.18-0032

37 Azmatullah A, Qamar FN, Thaver D, Zaidi AK, Bhutta ZA. Systematic review of the global epidemiology, clinical and laboratory profile of enteric fever. J Glob Health. 2015;5:020407. Medline:26649174 doi:10.7189/jogh.05.020407

38 Amicizia D, Arata L, Zangrillo F, Panatto D, Gasparini R. Overview of the impact of Typhoid and Paratyphoid fever. Utility of Ty2la vaccine (Vivotifß). JPMH. 2017;58:E1. Medline:28515625

39 Steele AD, Hay Burgess DC, Diaz Z, Carey ME, Zaidi AK. Challenges and opportunities for typhoid fever control: a call for coordinated action. Clin Infect Dis. 2016;62:S4-8. Medline:26933019 doi:10.1093/cid/civ976

40 Karoli R, Fatima J, Chandra A, Singh G. Salmonella hepatitis: an uncommon complication of a common disease. J Family Med Prim Care. 2012;1:160. Medline:24479030 doi:10.4103/2249-4863.104992

41 Ofori-Asenso R, Agyeman AA. Irrational use of medicines—a summary of key concepts. Pharmacy (Basel). 2016;4:35. Medline:28970408 doi:10.3390/pharmacy4040035

42 Coltart CEM, Lindsey B, Ghinai I, Johnson AM, Heymann DL. The Ebola outbreak, 2013-2016: old lessons for new epidemics. Philos Trans R Soc Lond B Biol Sci. 2017;372:20160297. Medline:28396469 doi:10.1098/rstb.2016.0297

43 Hein W. The Response to the West African Ebola Outbreak (2014-2016): A Failure of Global Health Governance? In: Vierck L, Villarreal PAPD, Weilert AKLLM, editors. The Governance of Disease Outbreaks: International Health Law: Lessons from the Ebola Crisis and Beyond. 1 ed. Baden-Baden: Nomos Verlagsgesellschaft mbH \& Co. KG; 2017.

44 Lesmanawati DAS, Veenstra P, Moa A, Adam DC, MacIntyre CR. A rapid risk analysis tool to prioritise response to infectious disease outbreaks. BMJ Glob Health. 2020;5:e002327. Medline:32513862 doi:10.1136/bmjgh-2020-002327

45 Abofaye MA. Outbreak severity index: The international response to the global outbreaks: University of Kentucky; 2015.

46 Kriss JL, Stanescu A, Pistol A, Butu C, Goodson JL. The World Health Organization Measles Programmatic Risk Assessment Tool-Romania, 2015. Risk Anal. 2017;37:1096-107. Medline:27439071 doi:10.1111/risa.12669 
47 Bruce Aylward R, Sutter RW, Cochi SL, Thompson KM, Jafari H, Heymann D. Risk management in a polio-free world. Risk Anal. 2006;26:1441-8. Medline:17184391 doi:10.1111/j.1539-6924.2006.00840.x

48 Bakar AA, Kefli Z, Abdullah S, Sahani M, editors. Predictive models for dengue outbreak using multiple rule base classifiers. Proceedings of the 2011 International Conference on Electrical Engineering and Informatics; 2011 17-19 July 2011.

49 Steinberg EB, Bishop R, Haber P, Dempsey A, Hoekstra R, Nelson J, et al. Typhoid fever in travelers: who should be targeted for prevention? Clin Infect Dis. 2004;39:186-91. Medline:15307027 doi:10.1086/421945

50 Hollingsworth TD, Ferguson NM, Anderson RM. Frequent travelers and rate of spread of epidemics. Emerg Infect Dis. 2007;13:1288. Medline:18252097 doi:10.3201/eid1309.070081

51 Patel TA, Armstrong M, Morris-Jones SD, Wright SG, Doherty T. Imported enteric fever: case series from the hospital for tropical diseases, London, United Kingdom. Am J Trop Med Hyg. 2010;82:1121-6. Medline:20519611 doi:10.4269/ajtmh.2010.10-0007

52 Public Health agency of Canada. Statement on international travelers and typhoid by the Committee to Advise on Tropical Medicine and Travel (CATMAT), 2014.

53 Suryapranata FS, Prins M, Sonder G. Low and declining attack rates of imported typhoid fever in the Netherlands 1997-2014, in spite of a restricted vaccination policy. BMC Infect Dis. 2016;16:731. Medline:27905890 doi:10.1186/s12879-016-2059-0 54 Brunette GW. CDC yellow book 2018: health information for international travel. Oxford: Oxford University Press; 2017.

55 Ochiai RL, Acosta CJ, Danovaro-Holliday M, Baiqing D, Bhattacharya SK, Agtini MD, et al. A study of typhoid fever in five Asian countries: disease burden and implications for controls. Bull World Health Organ. 2008;86:260-8. Medline: 18438514 doi:10.2471/BLT.06.039818

56 Bhutta ZA. Current concepts in the diagnosis and treatment of typhoid fever. BMJ. 2006;333:78-82. Medline:16825230 doi:10.1136/bmj.333.7558.78

57 Doherty M, Buchy P, Standaert B, Giaquinto C, Prado-Cohrs D. Vaccine impact: benefits for human health. Vaccine. 2016;34:6707-14. Medline:27773475 doi:10.1016/j.vaccine.2016.10.025

58 Greenwood B. The contribution of vaccination to global health: past, present and future. Philos Trans R Soc Lond B Biol Sci. 2014;369:20130433. Medline:24821919 doi:10.1098/rstb.2013.0433

59 Largeron N, Lévy P, Wasem J, Bresse X. Role of vaccination in the sustainability of healthcare systems. JMAHP. 2015;3:27043. Medline:27123188 doi:10.3402/jmahp.v3.27043 